High-Quality Music Synthesis," Journal of New Music Research, 27(3), (September 1998), pp. 211-238.

I have written about systems aspects of working with animation and music in Dannenberg, "Real Time Control For Interactive Computer Music and Animation," in Proceedings of The Arts and Technology II: A Symposium, Connecticut College, (February 1989), pp. 85-94, and Dannenberg and Rubine, "Toward Modular, Portable, Real-Time Software," in Proceedings of the 1995 ICMC, ICMA, (September 1995) pp. 65-72, and Fred Collopy has an interesting web site devoted to this topic. In the computer music languages and system area, see Dannenberg, "The Canon Score Language," Computer Music Fournal, 13(1), (Spring 1989), pp. 47-56 for an introduction to the idea of scores as programs and how temporal semantics can be added to a programming language to create a music language. This work was extended in Nyquist as described in Dannenberg "Machine Tongues XIX: Nyquist, a Language for Composition and Sound Synthesis," Computer Music Journal, 21(3) (Fall 1997), pp. 50-60. More recently, have turned to language support for realtime systems, and some of the most recen ideas are in Dannenberg, "A Language for Interactive Audio Applications," in Proceedings of the 2002 ICMC, ICMA, (2002), pp. 509-515.
I gave some examples of what I consider to be good examples of research-oriented software tools. More information can be found in Bencina and Burk, "PortAudio -- an Open Source Cross Platform Audio API," in Proceedings of the 2001 ICMC, ICMA, (2001), the PortMusic web site, Mazzoni and Dannenberg, "A Fast Data Structure for Disk-Based Audio Editing," in Proceedings of the 2001 ICMC, ICMA, (2001), pp. 107-110, James McCartney, "Rethinking the Computer Music Language: SuperCollider," Computer Music Journal, 26(4), (Winter 2002), pp. 61-68, the csounds.com web site, the Nyquist web site, Déchelle, Borghesi, De Cecco, Maggi, Rovan, and Schnell, "jMax: An Environment for Real Time Musical Applications," Computer Music Fournal, 23(3), (Fall 1999), pp. 50-58, Burk, "JSyn -- A Realtime Synthesis API for JAVA," in Proceedings of the ICMC, ICMA (1998), Cook and Scavone, "The Synthesis ToolKit (STK)," in Proceedings of the 1999 ICMC, ICMA, (1999) and the STK website, Wright and Freed (1997), "Open Sound Control: A New Protocol for Communicating with Sound Synthesizers," in Proceedings of the 1997 ICMC, ICMA, pp. 101-104 and the OSC web site, Lopez-Lezcano, "The Planet CCRMA Software Collection," in Proceedings of the 2002 ICMC, ICMA, pp. 138-141 and the PlanetCGRMA website.

\section{Impressions of ICMC 2003} Yuan Peiying

As the final notes of Steve Everett's Gamelan Asmaranda lingered in the air, signaling the end of the International Music Conference 2003, I was overwhelmed with a cascade of thoughts. What came to mind immediately was most definitely regret and remorse that there would possibly never be another chance to participate in such a conference in Singapore ever again. Thankfully, however, I had managed to learn many things from the conference and I am glad that I have been given this invaluable learning opportunity.

There were several memorable events that had taken place throughout the five eventful days of the conference. When attending concerts, what amazed me most was the realization that computer music is actually a very 'real' form of music. The sounds, although digitally enhanced and altered, are most realistic and are a reflection of the everyday sounds we come across. There is no shortage of compositions by various composers to prove this point. Rikhardur H. Fridriksson's Lidan II, showcased during the last day's evening concert, is one example. The sounds used had real-life origins, which were the coughs and gasps produced by the human vocal cords. Moreover, the piece was inspired from and a direct consequence of a period of bad health and respiratory disorder of the composer himself, thus highlighting the reality attached to the sounds of computer music.

sat on the bus the other day and was perturbed by the screeching noises of the brakes. I walked past a construction site this afternoon and for the first time, I wasn't irritated by the blast of sounds. Instead, my mind was imagining how would be able to use these sounds in my compositions. These are but two examples of how my participation in the conference has broadened my perception of music and triggered off much creativity and imagination.

The range of compositions presented was wide and a definite eye-opener. Besides more 'traditionally' computer music sounding works, like Apostolos Loufopoulos' Night Pulses, whose night sounds were quite distinctly simulated through computer mediums, there were slightly more avant-garde sounding works, as well as works that challenged the norm and brought in other influences. Works like Naotoshi Osaka's Mirrors for hichiriki (a traditional Japanese wind instrument) 
Paul Rudy's Fantasie for erhu and Pierre Alain Jaffrennou's Study for pipa drew distinct inspiration from traditional instruments of the Chinese and Japanese civilizations. However to a certain extent, one can say that exploration into these instruments have been made before and there is relatively little that composers can offer in writing new music and exploiting new sounds from these instruments. On the other hand, there were composers who dared to divulge into the less explored. Of particular mention is Shahrokh Yadegari's Traditionally Electronic. The title itself suggests a juxtaposition of traditional and electronic elements, which is what takes place between the Indian/Persian violin and vocals, and the computer. The result of this unusual marriage of Indian performance technique (with its Persian origins) with the 'Western' computer is a delightful creation of new sounds and spiritual awareness. Combined with the intricate setup of lush, rich-coloured rugs and a drone-box to boot, the spiritual realm created by electronically processed traditional violin and female vocals was unforgettable. It was as if the audience was being transported into a different world and experiencing a certain degree if soul-enlightenment. Such is the power of the combination of elements.

Another piece which struck me was Mark Applebaum's Pre-composition, a hilarious work that is in actual fact an ironic and sarcastic exorcism of the often irrational 'council of elders' in the composer's head. This work for 8-channel tape tickled so many bones that I was still laughing to myself about it back on my way home. But what made it so successfully sarcastic was that it highlighted exactly the way computer music sounds when clichéd and simplified. The twist at the end involving a 'radical' method of ending that particular 'composition' was, in itself, refreshing, one of those things that just make you go 'wow, why didn't I think of that?' This piece earns points for being original in concept.

Although all the pieces showcased are masterpieces themselves and deserve much credit and recognition, there is this biasness on my side as an audience to particularly remember pieces that, besides providing audio pleasure, are accompanied by visual images too Several pieces had live performers on stage or were in the form of videos, bu by far the most successful combination of audio and visual mediums must have been the silent movie screened on Italian night, with live music provided by the Edison studio. The music was well-paced, suited to complement the film, and was also effective in creating suspense in this horror film. The drama created would not have been possible without the excellent live music provided that night. Although it is true to say that when watching a film, the visual impact always hits hardest, it is the music and sounds that complete the whole experience and help paint a certain, complete atmosphere. As much as the conscious mind refuses to listen to it carefully when it is being pre-occupied with processing what showing on screen, the sub-conscious is actually processing it. So even if the audience walks away not distinctly remembering any of the music, credit must still go to the musicians who worked hard in letting audiences enjoy the movie tremendously.

It is weird to mention in this essay that it is almost always hard for audiences to know when a piece of music has properly ended. Applause at the end of the song often comes hesitant and half-hearted, because audiences are often in doubt as to whether the piece has formally come to an end. An analysis into this 'problem' shows that it is not so much that people have been bored by the music or do not like it. Very often this is not the case. People may be very willing to show their appreciation of the work through thunderous applause, but are not sure of when to show their appreciation. Perhaps it is the use of silence and space in computer music that makes the ending so ambiguous. The three dimensional concept of space, when used in an audio medium, is effective to create musical tension and anticipation, but it evolves into a problem for audiences at the end. The simple question of 'has the music ended?' becomes a problem then. This is non-existent for traditional Western works because of certain 'oftenused', stylistic methods of ending a piece, but computer music is different because it is so divergent in styles and concepts. Furthermore, the lack of a person to cue the audience to applause, a common practice for Western classical performances, adds on to the ambiguity of the end of the composition.

On the whole, my participation in this conference has been a definite eye-opener From a person who knew relatively little about computer music, or to stretch it a little, never really liked electronic sounds, to a person who can now hear a sound and imagine how control of the sound could turn it into music, I am extremely glad that I have been exposed to computer music through this conference. The wealth of creativity that comes from immersing myself and soaking up as much music as possible from five consecutive days may be straining but definitely worth it. Now, to stretch my imagination further, maybe, if I work hard enough, I might have the chance to travel overseas and participate in such a conference again in the next few years! 